\title{
Instructional challenges in criminology and forensic science
}

\section{Opinion}

The past couple of decades have ushered in dramatic changes for both practitioners and educators in the fields of criminology and forensic science. The rapid pace of technological advancement and discovery, compounded by the ever-changing needs and expectations of administrators and student populations serve to represent greater barriers and challenges for the professionals working in these and related fields. The goal of educational program administrators is typically to ensure a high-quality education, while simultaneously promoting recruitment and maximizing retention. The problems this poses for the modern criminologist are twofold:

a) The role of criminology in modern society has been dramatically changed - in part, by popular culture. By effectively integrating the popular culture associated with criminology and forensic science into the learning experience, the educators, student populations and administrators all stand to benefit; and

b) Educational technologies, such as the availability of the internet and related educational services, have begun to change the expectations of students regarding the function and quality of the criminology-related education.

More interdisciplinary students are now attracted to courses in criminology and forensic science, and they expect a more dynamic learning experience, with greater breadth, and openness to multicultural understandings of the subject matter. Much of the recent change in student populations is due, in part, to a media-driven curiosity. From Bollywood to Hollywood, crime, criminology and various aspects of forensic science saturates the big and small screens. Audiences around the world are more fascinated with crime and the science surrounding it than ever before. As a criminologist with 20 years of experience in higher education, I have seen a profound change in the expectations of new students seeking out courses in this field. After speaking with various colleagues from around the world, and continually polling my students about their motivations or interests in these courses, the thing that stands out the most is the magnitude of pop culture in shaping the
Volume 4 Issue 2 - 2017

Jim Taylor
Ohio University Zanesville, USA

Correspondence: Jim Taylor, Ohio University Zanesville, 1425 Newark Rd Zanesville, OH 4370I, USA, Tel 740-588-1468, Email taylori2@ohio.edu

Received: March 04, 2017 | Published: March 07, 2017

interests, curiosity and expectations of modern criminology students. This curiosity serves to attract students from multifarious backgrounds and majors to these courses. On the one hand, this puts most faculty at somewhat of a disadvantage in living up to the expectations and excitement of a popular crime drama. However, an industrious and creative faculty member is well-served by integrating aspects of popular culture into the learning experience. For instance, by having students draw upon their own knowledge of criminology in the movies and $\mathrm{TV}$, and relate it to course content, it presents a vantage point for the criminologist or forensic scientist to either expose the errors and myths of the media portrayals, or alternately discuss their merits In the end, this type of approach caters to stated student interests, serves the educator in demonstrating important concepts and methods in a meaningful way, while potentially serving the administration's goals of student retention and quality of instruction.

\section{Acknowledgments}

None.

\section{Conflicts of interest}

None. 